Bio - grafía. Escritos sobre la Biología y su Enseñanza. ISSN 2027-1034

Edición Extraordinaria. p.p. 230 - 236

Memorias del IX Encuentro Nacional de Experiencias en Enseñanza de la Biología y la Educación Ambiental. IV Congreso Nacional de Investigación en Enseñanza de la Biología.

\title{
CATEGORÍA NATURALISTA EN EL RECONOCIMIENTO DE HUELLAS REALIZADO POR NIÑOS Y NIÑAS WAYUU, EN EL CONTEXTO ESCOLAR.
}

\section{CATEGORY NATURALIST IN THE RECOGNITION OF FINGERPRINTS MADE BY WAYUU CHILDREN, IN THE SCHOOL CONTEXT}

\author{
Andrea Castillo Rodas ${ }^{1}$ \\ Andrés Arturo Venegas Segura ${ }^{2}$
}

\section{RESUMEN.}

El presente artículo presenta las ideas y saberes de los niños y niñas de grado quinto de la Comunidad Indígena Wayúu (Loma Fresca y Tocoromana) del resguardo Perrapu en el Municipio de Riohacha, Guajira, con respecto al reconocimiento de los animales a través de los rastros y huellas. Los Conglomerados de Relevancias aportaron la metodología de análisis del discurso de los estudiantes. La presente comunicación se enmarca en la categoría Naturalista que surgió de la investigación "Historias Detrás de una Huella, Reconocimiento de los Saberes Wayúu Relacionados a la Fauna a Partir de Rastros y Huellas".

En la recuperación de la experiencia de los infantes se presentaron juicios de valor, aspectos físicos, mentales, espirituales, emocionales, éticos, estéticos, y elementos de la naturaleza, los cuales ponen de manifiesto su voz. Donde sus conocimientos son la cristalización de procesos históricos y sociales que han constituido formas particulares de comprender los mundos de la comunidad Wayuu, que configuran dinámicas y realidades propias. De esta manera, es posible argumentar que los saberes tradicionales y ancestrales, deben ser incluidos en la clase de ciencias.

PALABRAS CLAVE: Comunidad Wayuu, Infancia; Ideas del Mundo Natural, Conglomerado de relevancias.

\section{ABSTRACT.}

This article presents the ideas and knowledge of fifth grade children of the Wayúu Indigenous Community (Loma Fresca and Tocoromana) of the Perrapu shelter in the Municipality of Riohacha, Guajira, regarding the recognition of animals through traces And footprints. The Conglomerates of Relevance provided the methodology for analyzing the students' discourse. This communication is part of the Naturalist category that emerged from the research "Stories behind a Footprint, Recognition of Wayuu Knowledge Related to Fauna from Traces and Footprints."

In the recovery of the infants' experience, judgments of value, physical, mental, spiritual, emotional, ethical, aesthetic aspects and elements of nature were presented, which reveal their voice. Where their knowledge is the crystallization of historical and

\footnotetext{
${ }^{1}$ Magister en Educación. Licenciada en Biología. Universidad Distrital.

2 Doctor en Educación. Licenciado en Física y Antropólogo. Universidad Distrital.
} 
Bio - grafía. Escritos sobre la Biología y su Enseñanza. ISSN 2027-1034

Edición Extraordinaria. p.p. 230 - 236

Memorias del IX Encuentro Nacional de Experiencias en Enseñanza de la Biología y la Educación Ambiental. IV Congreso Nacional de Investigación en Enseñanza de la Biología.

social processes that have constituted particular ways of understanding the worlds of the Wayuu community, which configure their own dynamics and realities. In this way, it is possible to argue that traditional and ancestral knowledge should be included in the science class.

KEYWORDS: Wayuu Community, Childhood; Natural World Ideas, Conglomerate of Relevance.

\section{INTRODUCCIÓN}

El objetivo de este artículo es mostrar la interpretación y construcción de la categoría naturalista sobre el reconocimiento de las huellas de los animales, en la investigación "Historias detrás de una huella, reconocimiento de los saberes Wayúu relacionados a la fauna a partir de rastros y huellas". El reconocimiento de las huellas y rastros de los animales tiene implicaciones en los saberes y conocimientos de tipo biológico y socio - cultural de los estudiantes siendo referentes en la construcción del conocimiento escolar. En este sentido, la construcción del conocimiento natural, es el pilar del conocimiento biológico en el contexto escolar y este se logra mediante las experiencias propias de los estudiantes. Así nace la necesidad de constituir la categoría naturalista (Molina, 2000; 2002) que explique los procesos en el reconocimiento de las huellas, mencionados por parte de los estudiantes.

\section{REFERENTE CONCEPTUAL Y METODOLOGÍA}

Reconocimiento de las huellas y su importancia en la cultura y el contexto escolar: Desde lo biológico podemos definir la huella como una impresión en el suelo de la patas de un animal, la generación de estas dependen de muchos factores como: el animal, el tipo de suelo, las condiciones climáticas y atmosférica, entre otras; estas impresiones suelen presentarse en terrenos húmedos como la arena o el barro y se constituyen en un rastro que evidencia la existencia de un animal en una zona. (Berker y Dalponte, 1999; Navarro et al, 2000)

Estas huellas le permiten al investigador reconocer dos tipos de factores, los dependientes, relativos al animal como son el sexo, edad, marcha (paso, trote, galope o salto) y la pata que produjo la impresión (anterior, posterior, derecha o izquierda), y el segundo, los independientes, referidos a causas externas como factores atmosféricos, propiedades del terreno, conformación del sustrato (arena, piedra, barro, etc.) y tiempo de impresión de la huella; también le permite a los investigadores determinar la fauna silvestre de un lugar específico, los índices de abundancia basado en las huellas y la distribución de los animales. (Navarro et al, 2000)

Desde la parte cosmológica, los animales hacen parte importante de la mitología de los pueblos encontrándolos en manifestaciones artísticas, sociales, bélicas 0 religiosas. Las comunidades admiran las cualidades de los animales y las otorgan a sus deidades mediante rituales. Esto convierte a los animales en elementos importantes dentro de la cultura encontrándolos dentro del mito, y generando referentes a nivel educativo y cotidiano. (De la Torre, 2003) 
Bio - grafía. Escritos sobre la Biología y su Enseñanza. ISSN 2027-1034

Edición Extraordinaria. p.p. 230 - 236

Memorias del IX Encuentro Nacional de Experiencias en Enseñanza de la Biología y la Educación Ambiental. IV Congreso Nacional de Investigación en Enseñanza de la Biología.

En este sentido el desarrollo de los saberes y conocimientos relacionados al reconocimiento de los rastros de los animales, permiten el desarrollo de la cultura y por tanto hacen parte del contexto cotidiano de los estudiantes, posteriormente del contexto escolar como concepto previo. (Carbonell y Torrealba, 2009)

Categoría Naturalista: el naturalismo se relaciona con la comprensión y explicación de la naturaleza y sus procesos desde lo empírico, utilizando teorías de las ciencias naturales para dicha explicación. (Zamora - Bonilla, 2000)

De acuerdo a lo anterior, esta categoría reconoce la respuesta de los estudiantes en las cuales se mencionan todos los procesos que posibilitan la generación de la huella, esto evidencia en los estudiantes su forma de relación con la naturaleza, así el estudiante relaciona su entorno y lo explica como un fenómeno, la huella no es concebida como un proceso no como un producto final, y como proceso se explican los factores que la producen, como el quien, el cómo etc. (Castillo, 2013). Esta categoría desde los planteamientos de Molina (2000) y Venegas (2012) se relacionan con los múltiples aspectos referidos a la diversidad de animales y plantas; las formas de nombrar y los modos de clasificar, entre las cuales se reconocen: nominales basadas en la experiencia; según la función que cumplen los seres de la naturaleza desde la ciencia escolar; desde la obtención de alimento, su composición, el tamaño, entre otras; desde los conocimientos empíricos de los organismos; desde las pautas de comportamiento y alimentación de los animales; desde las formas de captura, caza y pesca de diversos animales. Es importante apreciar que los conocimientos adquiridos en la escuela son retomados en este criterio. En algunas ocasiones estos saberes son relacionados con la cotidianidad de los infantes y sirven como elemento de diálogo incorporado en su discurso.

Diseño Metodológico: La metodología de este proyecto de investigación se encuentra enmarcada en un enfoque interpretativo (Bruner, Haste, 1990) en el cual se pretende el reconocimiento de los saberes y conocimientos (Ricoeur, 2006) presentes en los niños y niñas de quinto de primaria de la comunidad entorno a la fauna. Asimismo se retoman elementos de la etnografía como son la revisión documental, la encuesta, la encuesta semiestructurada, el dialogo, la observación no participativa y participativa, donde se evidencia la etnografía como proceso y como producto. El diseño metodológico del trabajo se desarrolló en 3 fases: documentación, campo y análisis. En la fase de análisis se realiza la generación de las categorías de análisis que emergen de las narrativas de los estudiantes donde emergen diversas categorías entre las cuales se destaca la naturalista, que se desarrolla en la presente comunicación.

\section{ANÁLISIS DE RESULTADOS E INTERPRETACIÓN: LOS MÉTODOS DE RECONOCIMIENTO DE LAS HUELLAS.}

De la investigación denominada "Historias Detrás de una Huella, Reconocimiento de los Saberes Wayúu Relacionados a la Fauna a Partir de Rastros y Huellas" surge la pregunta "¿Cómo reconoces las huellas?" con el fin de identificar los diversos métodos utilizados por los estudiantes para el reconocimiento de las huellas. Se reconocen cinco categorías de análisis: Naturalista, Biodiversidad, Espacial, Útil y Ecológica; como se mencionó anteriormente la comunicación solo atiende a la categoría naturalista. Cabe resaltar que por políticas de respeto a la integridad de los menores 
Bio - grafía. Escritos sobre la Biología y su Enseñanza. ISSN 2027-1034

Edición Extraordinaria. p.p. 230 - 236

Memorias del IX Encuentro Nacional de Experiencias en Enseñanza de la Biología y la Educación Ambiental. IV Congreso Nacional de Investigación en Enseñanza de la Biología.

sus nombres no se muestran, se realiza una denominación con una letra del abecedario.

\section{Categoría Naturalista.}

Para los niños y niñas el reconocimiento de las huellas está relacionado con la descripción de procesos vinculados a sus experiencias personales 0 a la percepción sensorial, los estudiantes explican lo que ven o viven y lo relacionan a la pregunta ¿cómo reconoces las huellas?:

"Reconocemos las huellas por medio de los animales como la vaca tiene otra huella el burro tiene otra y eso es la diferencia no podemos confundir la huella del burro con la huella de la vaca las huellas del burro son cerradas y las huelas de la vaca son abiertas (...)" (A)

En esta respuesta el estudiante reconoce las huellas a través de su percepción visual, además identifica las diferencias entre las huellas de un animal con otro, para ello toma como ejemplo la vaca (huella abierta) y el burro (huella cerrada), describiendo su forma y utilizando la comparación para explicar la diferencia.

Otra de las maneras en las cuales los niños explican sus experiencias personales es mediante el dibujo, como se ve en la imagen 1, allí, el estudiante explica la huella del chivo que es cercana a su cotidianidad y reafirma su conocimiento sobre este animal y su huella siendo capaz de dibujarla e identificarla.

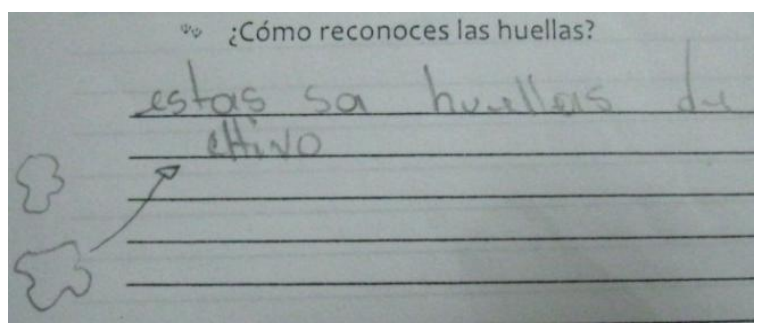

Imagen 1 Dibujo explicativos de la Huella del chivo (D)

Otra evidencia de lo expresado anteriormente es el dibujo de X (Imagen 2), en el cual por medio de la representación de la pata de perro, busca mostrar su conocimiento sobre la huella de este animal.

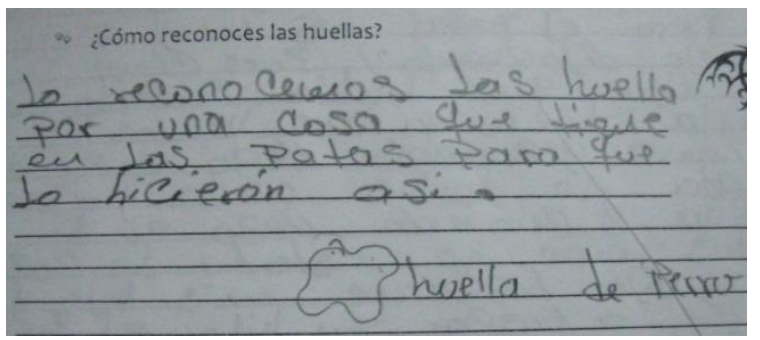

Imagen 2. Dibujo explicativos de (X)

Así, el estudiante reconoce las huellas gracias a que éstas tienen formas diferentes dependiendo del animal, el reconocimiento de las patas depende de los rasgos especiales que estas presentan: "La reconocemos (...) por una cosa que tiene en las 
Bio - grafía. Escritos sobre la Biología y su Enseñanza. ISSN 2027-1034

Edición Extraordinaria. p.p. 230 - 236

Memorias del IX Encuentro Nacional de Experiencias en Enseñanza de la Biología y la Educación Ambiental. IV Congreso Nacional de Investigación en Enseñanza de la Biología.

patas". Cuando el niño se refiere a "una cosa que tiene en las patas", se infiere que la identificación de las pisadas es debida a los rasgos únicos en cada animal.

Otro tipo de explicación es aquella que relaciona las imágenes acompañantes de la pregunta con la respuesta, como en el caso de (F): "Como conocemos el huella de este murcielago (...) en un rincon hay parece (...) en un pared". En ésta el estudiante responde vinculando la pregunta con la imagen 3 que la acompaña; aunque el murciélago no camina, si deja un rastro en la pared, a este rastro también lo podemos clasificar en la categoría de huella.

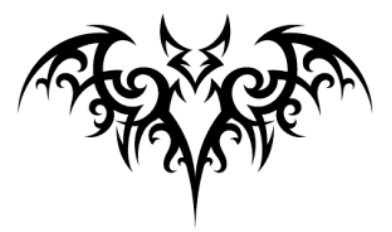

Imagen 3. Imagen acompañante a la pregunta.

Algunas explicaciones utilizan la analogía como herramienta, un ejemplo de ello es: "estas huellas son como huellas de pajarito" (G). En ésta el estudiante hace una analogía entre las huellas del murciélago y las de los pájaros, de esta forma, vincula ambos animales de acuerdo a su desplazamiento por medio del vuelo, por lo cual, sus patas deben ser iguales o similares, así la analogía permite relacionar lo cotidiano con lo desconocido, en este caso, la pata de los pájaros con la pata de los murciélagos.

La relación con las imágenes y la respuesta, también permiten que los niños y niñas describan el comportamiento y formas anatómicas poco conocidas, como se ve en la respuesta, "la reconoce como aguila y forma de gato cuando se colga en un palo de coco" (I). El niño distingue tres características del murciélago, la primera de ellas es su anatomía, comparándola con la del águila y la del gato, en segundo lugar se reconoce la palma de coco como hábitad natural del murciélago y por último se distingue un comportamiento propio de ellos como es el de colgarse; todas estas comparaciones y afirmaciones son posibles gracias a las experiencias personales y sensoriales de los estudiantes.

Las formas de las huellas determinan el comportamiento de los animales como se describe a continuación: "Yo conosco por que huellas esta en el suelo y (...) por donde pisa las vaca y (...) por la duerma y (...) por donde descansa" (L). El niño reconoce que las huellas son diversas y permiten identificar diferentes acciones en los animales como dormir, descansar y pisar.

Algo que también es referenciado como la huella es la forma del animal, como lo hace $\mathrm{Y}$ al afirmar: "este tipo de huellas es reconocido como murcielago el murcielago bien [Vive] en lugares oscuros", para este caso la imagen (3).

Las huellas también se relacionan con la locomoción, la capacidad que tienen los animales o personas de formar huellas es debida a su facultad de desplazamiento (caminar, pisar o pasar), un ejemplo es la expresión: "Por que cuando camina una gallina Yo digo por aquí paso una gallina de mi papá" (E). El estudiante hace referencia a su cotidianidad, y al proceso de caminar de la gallina para la generación de la huella. 
Bio - grafía. Escritos sobre la Biología y su Enseñanza. ISSN 2027-1034

Edición Extraordinaria. p.p. 230 - 236

Memorias del IX Encuentro Nacional de Experiencias en Enseñanza de la Biología y la Educación Ambiental. IV Congreso Nacional de Investigación en Enseñanza de la Biología.

Otro ejemplo es la afirmación de $\mathrm{H}$, "las reconocemos como la gata o tigre o la leopardo y la iguana cuando la lobo camina se le ven las huellas", así, el estudiante reconoce en el proceso de caminar la generación de la huella, también hace referencia a los animales cuadrúpedos a los que posiblemente relaciona más fácil con las huellas físicas de las patas.

Las características de las patas de los animales y pies de las personas también permiten reconocer las huellas por medio de la observación, éstas se relacionan para explicar el fenómeno de formación de huellas como lo dice K, "las reconocosco por que cuando camina van dejando las huellas y las reconosco por medio de sus pies 0 patas". De esta forma, el estudiante clasifica las huellas en pies y patas; diferenciando entre los animales y las personas a través de sus huellas. Lo anterior se ratifica con la afirmación:

"Yo reconosco la huella por que es distinta cuando es de una persona por ejemplo (...) una huella larga y flaca y con cinco dedos en seguida Yo saco Yo digo esa huella es de una persona (...)" (M).

Los tipos de locomoción también determinan el tipo de huella que puede generarse, así:

"Yo reconosco la huella de una persona (...) tiene 5 dedos tiene talon tiene uñas (...) la culebra la huella es de rastras es toda curbiada..." (N)

La forma de la huella depende del tipo de locomoción del animal, para este caso las huellas de la culebra presentan esa forma curva debido a que se arrastra por el suelo.

La experiencias personales aportan ideas sobre cómo los niños y niñas reconocen las huellas, ya que el entono brinda las herramientas necesarias para la generación de explicaciones, lo anterior, se hace evidente en las afirmaciones: "Las reconosco viendolas y tambien persiguiendolas y mi pueblo ven que animal o persona es" $(P)$ y "Biendolas" (V). En ambos enunciados los estudiantes describen su proceso desde las experiencias personales como la observación y la persecución, éstas les permiten reconocer el tipo de animal o la persona a la cual pertenece la huella, convirtiéndola en una marca única.

Lo anterior también es evidente en lo expresado por Q quien manifiesta: "La huella se reconoce por que cada animal tiene su propia huella especial". La huella se convierte entonces en una marca única que hace especial a cada animal frente a otros de su misma especie o especies diferentes.

\section{A manera de Conclusión}

La construcción de la categoría naturalista, permite interpretar las respuestas de los estudiantes de acuerdo a sus explicaciones empíricas y sensoriales en el reconocimiento de los rastros y huellas de los animales. Este aspecto sirve de punto de partida para la construcción del conocimiento biológico - escolar de la fauna.

Las respuestas de los estudiantes se encuentran muy relacionadas con el conocimiento biológico de los animales describiendo, su ecología, locomoción y anatomía.

Las analogías y las imágenes son importantes en la construcción de la estructura conceptual de los niños y niñas, brinda una herramienta valiosa para entender el 
Bio - grafía. Escritos sobre la Biología y su Enseñanza. ISSN 2027-1034

Edición Extraordinaria. p.p. 230 - 236

Memorias del IX Encuentro Nacional de Experiencias en Enseñanza de la Biología y la Educación Ambiental. IV Congreso Nacional de Investigación en Enseñanza de la Biología.

mundo y organizar el conocimiento en diversos campos. La información empírica y el reconocimiento de las huellas y los rastros de los animales del entorno, permiten que el estudiante explicar los animales y entornos en los cuales no se desenvuelven. Siendo las analogías y las imágenes una de las formas en las cuales los niños y niñas realizan el dialogo entre los conocimientos y saberes propios y previos de su cultura con los del aula.

\section{BIBLIOGRAFÍA}

Becker M. y Dalponte J.C. (1999). Rastros de mamíferos silvestres brasileiros: una guía de campo. Universidad de Brasilia, Brasil: Editora IBAMA. 180 p.

Bruner, J \& Haste H. (1990). La elaboración de sentido: construcción del mundo por el niño. Barcelona, España: Paidos.

Carbonell, F. y I. Torrealba (editores). (2009). Memoria del taller participativo sobre monitoreo de especies banderas globalmente amenazadas en la Comarca NgobeBugle. Proyecto de Capacitación de representantes de grupos y comités ambientales indígenas en el Caribe panameño, a favor del Parque Internacional La Amistad. San José, Costa Rica.

Castillo Rodas A. (2013). "Historias detrás de una huella" Reconocimiento de los saberes Wayúu relacionados a la fauna a partir de rastros y huellas. Universidad Distrital Francisco José de Caldas, Bogotá, Colombia.

De la Torre V., (2003) Animales en la mitología. Anales de la Real Academia de Ciencias Veterinarias de Andalucía Oriental Vol: 16 (1)

Molina, A. (2000). Conhecimento, Cultura e Escola: Um estudo de suas Inter-relações a partir das idéias dos alunos (8-12 anos) sobre os espinhos dos cactos. Tesis doutoral, Doutor em Educacao, Faculdade de Educação, Universidade de São Paulo, Brasil.

Molina, A. (2002). Conglomerado de Relevancias y formación científica de niños, niñas y jóvenes. En: Revista Científica, (4), 187-200.

Navarro J. y Muñoz J. (2000), Manual de huellas de algunos mamíferos terrestres de Colombia. Medellín Colombia: Editorial de Campo

Ricoeur, P. (2006). Teoría de la interpretación. Discurso y excedente de sentido. México D. F., Mexico: Siglo XXI.

Venegas, S.A.A. (2012). Criterios De Análisis en la Interpretación de las Ideas de Naturaleza con el Conglomerado De Relevancias. Revista Científica. 16, 130-140

Zamora - Bonilla J. (2000). El naturalismo científico de Ronald Giere y Philip Kitcher. Un ensayo de comparación critica. Revista de Filosofía, 3ra época, vol XIII, v. 24. Universidad de Complutense, Madrid, España. 